\title{
CHEMICAL COMPOSITION, ANTIOXIDANT ACTIVITY, AND FATTY ACID PROFILE OF COCOA NIBS
}

\section{Fernanda Côrrea Leal Penido $^{1}$ (D) , Isabelle Cristine Ramos Lourenço ${ }^{1} \mathbb{( D D}^{\text {, }}$, Lívia Mariana da Silva $^{1}{ }^{(D)}$, Cleverson Fernando Garcia $^{1}{ }^{(\mathbb{D})}$ and Flávia Augusta Guilherme Gonçalves Rezende ${ }^{1}$ $\triangle$ (1)}

${ }^{1}$ Chemistry Department, Centro Federal de Educação Tecnológica de Minas Gerais, Belo Horizonte, MG,, Brazil
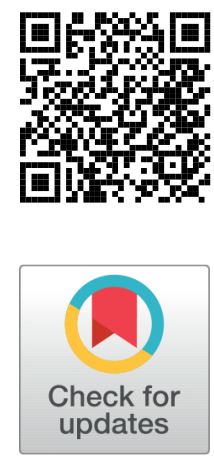

Received 4 June 2021

Accepted 18 June 2021

Published 30 June 2021

Corresponding Author

Flávia Augusta Guilherme

Gonçalves Rezende, flaviagoncalve

s@cefetmg.br

DOI 10.29121/

granthaalayah.v9.i6.2021.4024

Funding: This research received funding from $\mathrm{CNPq}$ and

CEFET-MG.

Copyright: (C) 2021 The Author(s). This is an open access article distributed under the terms of the Creative Commons Attribution License, which permits unrestricted use, distribution, and reproduction in any medium, provided the original author and source are credited.

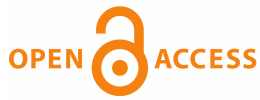

\section{ABSTRACT}

Cocoa nibs (Theobroma cacao L.) are the cocoa beans after being fermented, dried, broken into small pieces, and then toasted. The cocoa nib composition is primordial for producers, industry, and final consumers because it affects the final quality of the raw material and any derivative product. The chemical composition was analyzed using gravimetric, Soxhlet, Kjeldahl, and ScharrerKürschner methods. The results showed that the cocoa nibs studied were rich in lipids (44.02 $\pm 5.22 \%$ ), followed by carbohydrates $(25.30 \%)$, raw fiber $(12.85 \pm 3.67 \%)$, protein $(10.73 \pm 1.80 \%)$, and ash content $(2.58 \pm 0.15 \%)$. The fatty acid profile was determined by gas chromatography and showed the presence of palmitic, stearic, and oleic acids. The low moisture content (4.52 $0.12 \%)$ and total titratable acidity $(2.25 \pm 0.45$ meq NaOH $100 \mathrm{~g}-1)$ contributed to the low count of microorganisms, which may give cocoa nibs a longer shelf life. Additionally, it presented high antioxidant activity, with a total phenolic content of $843.45 \pm 11.85 \mathrm{mg}$ gallic acid / $100 \mathrm{~g}$ extract and $89.42 \pm 0.02 \%$ iron reducing power.

Keywords: Cocoa Nibs, Teobroma cacao, Food Composition, Phenolic Compounds

\section{INTRODUCTION}

The cocoa is a tropical fruit from the cocoa tree (Theobroma cacao L.), its beans and their derivative products are essential for the chocolate industry. Thus, beans have high commercial value and are a relevant commodity for many countries Afoakwa et al. (2013)

The cocoa nib processing starts postharvest, with the pulp removed and the fermentation of the beans, followed by drying and roasting. The fermentation lasts from three to seven days. During this step, which is important to determine cocoa beans quality, microorganisms produce a large number of volatile compounds and flavor 
precursors Caporaso and Al (2018), Marseglia et al. (2020). Drying reduces the moisture of beans and increases their shelf life. After that, they are broken to reduce the size of the kernel. Then, the nibs are roasted more evenly and with less energy expenditure because they are already in small pieces Nurhayati and Apriyanto (2021). During the roasting step $\left(120\right.$ to $150{ }^{\circ} \mathrm{C}$ ), the Maillard reaction is promoted, undesirable volatile acids are removed, and enzymes that can degrade cocoa butter are inactivated. However, it can affect the final sensorial quality and may cause the loss of phenolic compounds in the product [Mustiga and Al (2019), Zzaman et al. (2014) .

Cocoa quality is determined by factors such as being well fermented, drying until the obtainment of appropriate moisture content, absence of stranger odors and mold contamination Agus et al. (2018). The characterization of phytochemical compounds in cocoa beans may be a fundamental tool for their quality evaluation.

Cocoa nibs have a specific composition that englobes lipids, carbohydrates, proteins, minerals, and bioactive compounds with antioxidant activities Caprioli et al. (2016), Zzaman et al. (2014). Cocoa butter is the lipid constituent of cocoa beans, and it has industrial importance due to its unique physical properties., which are related to fatty acid composition, predominantly palmitic, stearic, and oleic acids Jia et al. (2019). The carbohydrate and protein contents in cocoa nibs are important in the development of the specific flavor and aroma of chocolates and other derivative products. The presence of fibers is also relevant because it makes cocoa nibs an attractive food from a prebiotic point of view. The mineral constituents represented by ash content reveal some production and processing characteristics Marseglia et al. (2020). Also, the determination of the cocoa bean composition is essential to obtain chocolate and other derivative products with high quality.

Moreover, cocoa beans are rich in phenolic compounds and other components with antioxidant properties. The ingestion of food rich in antioxidant agents is associated with a decrease in many diseases, such as diabetes and cardiovascular, respiratory, and neurological diseases Takahashi et al. (2020). Another relevant parameter when evaluating the antioxidant properties is iron-reducing power, which measures the capability to reduce iron ions and is responsible for avoiding radical formation Rezende et al. (june. 2019).

With the increasing use of cocoa nibs in the diet and growth of the origin chocolate market in Brazil, the present study aimed to determine the chemical composition, total phenolic compounds, iron reducing power, acidity, and microbiological quality of cocoa nibs produced on a farm producer from Ilhéus in the south of Bahia, Brazil.

\section{MATERIALS AND METHODS}

\subsection{SAMPLES AND REAGENTS}

The cocoa nibs were obtained from a cassava chocolate manufacturer in the city of Ilhéus, Bahia (BA) state, Brazil. All chemicals (analytical grade) were from $\operatorname{Merck}^{\circledR}$ (Darmstadt, Germany), and the culture media were from Acumedia (Lansing, 
MI, USA).

Half of the $1 \mathrm{~kg}$ crude sample of cocoa nibs was ground in a blender to reduce particle size and homogenize. After that, it was quartered to acquire the laboratory sample (80 g).

\subsection{METHODS}

\subsubsection{PHYSICAL-CHEMICAL ANALYSES}

Total titratable acidity (TTA) was determined by extracting the 1-g sample with distilled water $(100 \mathrm{~mL})$ and titrating it with $\mathrm{NaOH}(0.1 \mathrm{~N})$. The moisture content of cocoa nibs was determined in triplicate by the oven drying method at $110{ }^{\circ} \mathrm{C}$ using 6-g samples. The ash content was determined in a muffle furnace at $550{ }^{\circ} \mathrm{C}$. The lipid content was determined in the Soxhlet apparatus using hexane $(200 \mathrm{~mL})$ as the solvent. The Kjeldahl method was performed to determine the protein content, using a nitrogen conversion factor (6.25) (AOAC, 2016). Raw fiber determination was performed using the Scharrer-Kurschner method, using nitric acid, trichloroacetic acid, and acetic acid for hydrolysis Angelucci and Al (1987).

\subsubsection{COCOA BUTTER FATTY ACID PROFILE}

Cocoa butter fatty acids were converted into methyl esters, using a solution of $\mathrm{BF}_{3}$ in methanol (13-15\%) (Sigma-Aldrich) and their derivative profile was determined by gas chromatography (Agilent Technologies 7890A coupled to an Agilent Technologies 5975C mass spectrometer equipped with a Triple-Axis Detector; system fitted with an HP-5MS). The lipid sample (1 mL) obtained after methylation of cocoa butter fatty acids was injected, with a total retention time equal $28 \mathrm{~min}$. The column used was HP-5MS with 5\% phenyl methyl siloxane $30 \mathrm{~m}$ long. The split rate injector operated at $1 / 50$ at $220^{\circ} \mathrm{C}$. The interface temperature was $280^{\circ} \mathrm{C}$. The carrier gas was helium. Peak identification was performed by comparison with fatty acid methyl ester (FAME) C14 - C22 (Supelco-18917) standards.

\subsubsection{IRON REDUCING POWER AND TOTAL PHENOLIC CONTENT ASSAYS}

To each 5-g sample, ethanol ( $60 \mathrm{~mL})$ was added, and the mixture was stored ( $24 \mathrm{~h})$ in a refrigerator. After that, the content was filtrated, and the procedure was repeated by adding ethanol $(60 \mathrm{~mL})$ to the retained material followed by $24 \mathrm{~h}$ in the refrigerator. Finally, the mixture was filtered, and the filtrate was rotavapped to dryness and transferred to Petri dishes.

The iron reducing power assay was performed using phosphate buffer $\mathrm{pH}$ 6.6, potassium ferricyanide solution $(1 \% \mathrm{w} / \mathrm{v})$, trichloroacetic acid $(10 \% \mathrm{w} / \mathrm{v})$, and ferric chloride (0,1\% w/v) Oyazu and Journal Of Nutrition (1986), Sande et al. (2016). The absorbance was read at $700 \mathrm{~nm}$. 
The total phenolic content was determined using the Folin-Ciocalteu methodology Gao and Al (2000), Sande et al. (2016) . The absorbances were read (760 nm) and the result was expressed as $\mathrm{mg} / 100 \mathrm{~g}$ gallic acid equivalents (GAE).

\subsubsection{MICROBIOLOGICAL ANALYSES}

The microbiological analyses were conducted to search for total and fecal coliforms (by the most probable number - MPN - a method for total coliforms, thermotolerant coliforms, and E. coli in foods), Salmonella spp. (by the presence/absence method for Salmonella in foods), molds and yeasts, and aerobic mesophilic bacteria (by the standard count method) Silva and Al (2018) and compared to microbiological specification from legislation "Resolução RDC No 12, De 02 De Janeiro De" (2001) .

\section{RESULTS AND DISCUSSIONS}

Cocoa nib TTA was 2.25 meq NaOH $100 \mathrm{~g}^{-1}$. A study found that the acidity of Brazilian cocoa nib increased during the fermentation process and reached a value of 2.88 g of acetic acid/100 g) Peláez et al. (2016). During this process, organic acids diffuse into the beans, and these acids cannot disappear during the drying step Nurhayati and Apriyanto (2021). However, the longer drying and roasting processing, the lower acetic acid concentration and, consequently, total acidity Abballe and Al (2020, 2021).

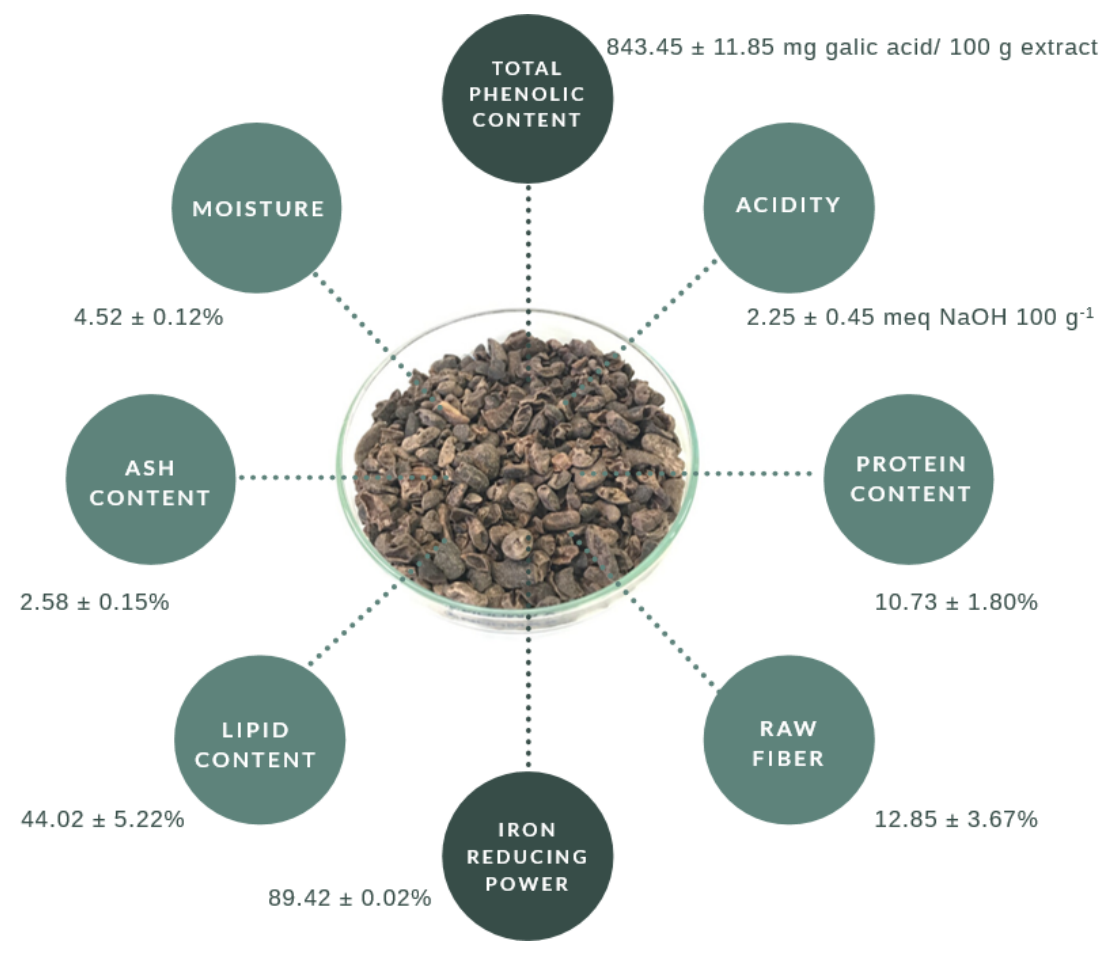

Figure 1 Centesimal composition of cocoa nib samples 
The obtained results for the centesimal composition of cocoa nibs (Figure 1) showed a moisture content of $4.52 \%$. Agus et al. (2018) found a lower moisture content for roasted cocoa beans (2.45\%). Although our result was higher, it was according to Brazilian legislation that allows a maximum value of $8 \%$ moisture for cocoa bean commercialization Brasil et al. (2008). Delgado-Ospina and Al (2020) found moisture contents between 1.2 and 6.2\%. The variation occurred because it depends on the conditions and the duration of the process. When the moisture content of cocoa beans reached approximately $7 \%$, the drying step performed well. The moisture content is an important parameter since a lower moisture content ensures a longer shelf life due to less microbial growth and less enzymatic activity Afoakwa et al. (2013).

The ash content of cocoa nib samples (2.58) was lower than the value found in roasted cocoa beans (3.36\%) Agus et al. (2018). Afoakwa et al. (2013) reveal that the fermentation step contributes to significantly reducing the ash content.

The lipid content of cocoa nib samples (44.02) was higher than the lipid content in roasted cocoa beans (30\%) Agus et al. (2018) and fermented and unroasted cocoa beans (24.65\% to $42.13 \%$ ) Caprioli et al. (2016). The lipid content is a primordial parameter in the determination of the price of fermented cocoa Afoakwa et al. (2013).

The protein content was 10,73\%. Caprioli et al. (2016), when analyzing cocoa beans from Cameroon, found similar values of protein content $(11.7 \%$ to $13.35 \%)$ in samples of cocoa beans. The highest protein value was found for the Ivory Coast sample (15.7\%), and the lowest for the Dominican Republic cocoa (11.8\%) Bertazzo and Al (2011). Another study with cocoa from Ghana also found higher protein contents for the Forasteiro sample (17.44\%), Criollo (16.49\%), and Trinitario (16.16\%) Oracz and Nebesny (2019). During fermentation, the protein content decreases significantly. Microbiological and enzymatic reactions, such as hydrolysis by proteases, contribute to this reduction Bertazzo and Al (2011). Roasting also promotes a reduction in protein amount due to the Maillard reaction Torres-Moreno and Tarrega (2021).

The concentration of raw fiber in the cocoa nib samples was $12.85 \%$. The fiber content usually varies according to the variety and processing that the cocoa beans undergo. The roast cocoa bean samples analyzed by Valiente and Al (1994) showed $16.01 \%$ fiber content. The cocoa fiber has significant hypolipidemic action and hypocholesterolemic effect.

The carbohydrate content $(25.30 \%)$ was determined by difference. The content of carbohydrates from cocoa samples obtained from different regions of Cameroon varied between $24.35 \%$ and $43.35 \%$ Caprioli et al. (2016). Agus et al. (2018) found a higher carbohydrate content in roasted cocoa beans (43.03\%). During the roasting step, the formation of flavor precursor compounds, initially produced during fermentation, increases through the Maillard reaction. Thus, heat treatment, which reduces sugars and free amino acids or short chain peptides, contributes to the decrease in carbohydrate content Marseglia et al. (2020). 
The main fatty acids found in cocoa nibs were stearic (C18:0; retention time $\left(\mathrm{t}_{R}\right)$ $=15,839 \mathrm{~min})$, palmitic (C16:0; $\left.\mathrm{t}_{R}=12,717 \mathrm{~min}\right)$, and oleic $\left(\mathrm{C} 18: 1 ; \mathrm{t}_{R}=15,442 \mathrm{~min}\right)$ acids. Although the method used in the present study was not able to identify other fatty acids, the results of the samples' fatty acid composition are in agreement with the results found in a previous study Caprioli et al. (2016). Cocoa butter is rich in equal parts of palmitic (C16:0), stearic (C18:0), and oleic (C18:1) acids Naik et al. (2014). The saturated fatty acids palmitic and stearic acids have melting points of $62{ }^{\circ} \mathrm{C}$ and $68^{\circ} \mathrm{C}$, respectively, and the unsaturated fatty acid oleic acid has a melting point of $16{ }^{\circ} \mathrm{C}$. This composition is desirable and unique, and it causes the chocolate to be solid at room temperature and melt when in contact with the mouth Jia et al. (2019), Mustiga and Al (2019). The presence of unsaturated fatty acids, such as oleic acid, aggregates higher nutritional value to the cocoa nibs.

Cocoa butter is also composed, in a smaller proportion, of polyunsaturated fatty acids, such as arachidic, palmitoleic, and linoleic acids Naik et al. (2014). However, these polyunsaturated fatty acids were not found in the present study. The methyl ester of arachidic acid was not part of the standards used in the present characterization. It might be present, but without the standard and the confirmation by the NIST library, it was not possible to identify this fatty acid. Environmental conditions influence lipid composition. The cocoa butter from Brazil is characterized by a high content of oleic acid, so it is called "soft" cocoa butter Mustiga and Al (2019).

Cocoa nibs presented a high level of iron-reducing power, $89.42 \%$ (Figure 1 ), which indicates the presence of natural antioxidant compounds in the composition. This result shows that cocoa nibs have a reducing capacity, which suggests potential antioxidant activity Boutennoun et al. (2017). The high iron reducing power may be related to the formation of new substances in the Maillard reaction that are capable of donating electrons or preventing free radical chain reactions during cocoa nib roasting Oracz and Nebesny (2019). This reaction is associated not only with the formation of compounds with antioxidant properties but also with sensory aspects, which are characteristic of the product Godočiková et al. (2019).

Phenolic compounds present in cocoa nibs are essential for the development of a typical aroma of chocolate Caporaso and Al (2018), Nurhayati and Apriyanto (2021). Cocoa nibs also presented a high phenolic content (843.43 mg gallic acid/100 g extract) (Figure 1 ). This result corroborated the research that studied the total phenolic content of cocoa beans from Indonesia, Papua New Guinea, and China, and found an average of total phenolic content ranging from $81.2 \mathrm{mg} / 10 \mathrm{~g}$ to 301.01 $\mathrm{mg} / 10 \mathrm{~g} \mathrm{Gu}$ et al. (2013).

Urbańska and Kowalska (2019) also measured the level of total phenolic content from roasted cocoa beans of the Dominican Republic, Ghana, Venezuela, Colombia, and Ecuador. The best result was obtained from Colombian cocoa beans (3781 $\mathrm{mg} / 100 \mathrm{~g}$ ), and the lowest result was obtained from Venezuelan cocoa beans (996 $\mathrm{mg} / 100 \mathrm{~g}$ ). These results were higher than those found in this study because they tested whole cocoa beans, while the present study evaluated only cocoa nibs. Accord- 
ing to the authors, the reduction in the size of the cocoa beans promotes a significant decrease in the level of total phenolic compounds. This loss can be explained by the influence of oxygen and light incidence, which are responsible for the degradation of these compounds. The fermentation step also reduces the phenolic content of cocoa beans Nurhayati and Apriyanto (2021).

Neither coliforms (result < $3 \mathrm{MPN} / \mathrm{g}$ ) nor Salmonella spp. were detected in the cocoa nib samples. Molds and yeasts were found in the samples with counts of $1.07 \times$ $10^{3} \mathrm{CFU} / \mathrm{g}$. Aerobic mesophilic bacteria were also found and exhibited a count of 9.77 $\times 10^{3} \mathrm{CFU} / \mathrm{g}$. Molds, yeasts, and mesophilic bacteria are indicator microorganisms that, when found in foods, can provide information on the possibility of contamination with pathogenic or deteriorating microorganisms, in addition to indicating inadequate sanitary conditions during processing, production, and/or storage Franco et al. (1996). Although these microorganisms were found on cocoa nib samples in low counts, the cocoa nibs evaluated were suitable for human consumption.

The low counts of microorganisms can be a consequence of the drying and roasting steps, which are critical points of control Lima et al. (2012). Therefore, the low count of aerobic mesophilic bacteria indicates that roasting was performed well. The presence of mold and yeasts, even in low counts, can be indicative that the package and storage were not adequate. In the composition of the microbiota of fermented cocoa beans and shells, a wide variety of microorganisms have been observed, including enterobacteria, total aerobic mesophiles, total aerobic thermophiles, acetic bacteria, spore-forming bacteria, lactobacilli, lactococci, fungi, and yeasts Delgado-Ospina and $\mathrm{Al}$ (2020).

\section{CONCLUSIONS}

Lipids were the most abundant nutrients found in the cocoa nib samples. The fat present in cocoa butter contained mainly palmitic, stearic, and oleic acid. The second most abundant macronutrient was carbohydrate, followed by protein and fiber. The presence of carbohydrates and protein, together with the low humidity and the high temperature of the roasting process, favor the Maillard reaction, which is responsible for the production of volatile compounds and the characteristic flavor. The increase in acidity during fermentation not only contributes to the flavor but also favors the low counts of microorganisms found in cocoa nibs. The presence of fiber and phenolic compounds, together with the iron reducing power, make cocoa nibs an attractive food from a nutritional and functional point of view.

\section{CONFLICTS OF INTEREST}

The authors have declared that no competing interest exist. 


\section{ACKNOWLEDGEMENTS}

This work was financially supported by the National Council for Scientific and Technological Development (CNPq), and Centro Federal de Educação Tecnológica de Minas Gerais (CEFET-MG). The cocoa nib samples were donated by Capela Velha Farm.

\section{REFERENCES}

Abballe, C. E., \& Al. (2020, 2021). Cocoa Beans And Derived Products: Effect Of Processing On Polycyclic Aromatic Hydrocarbons Levels. Lwt., 135(July).

Afoakwa, E. O., et al. (2013). Cocoa Beans As Affected By Pulp Pre-Conditioning And Fermentation. Journal Of Food Science And Tecnhology. Chemical Composition And Physical Quality Characteristics Of Ghanaian, 50(6), 1097-1105.

Agus, B. A. P., Mohama, D. N. N., \& Journal Of Food Measurement And Characterization. (2018). Hussain, N. Composition Of Unfermented, Unroasted, Roasted Cocoa Beans And Cocoa Shells From Peninsular Malaysia., 12(4), 2581-2589.

Angelucci, E. E., \& Al. (1987). Análise Química De Alimentos (Manual Técnico). Campinas: Instuto De Tecnologia De Alimentos (ITAL).

Bertazzo, A. E., \& Al. (2011). The Content Of Protein And Non-Protein (Free And ProteinBound) Tryptophan In Theobroma Cacao Beans. Food Chemistry., 124(1), 93-96.

Boutennoun, H. E., Al, \& Arabian Journal Of Chemistry. (2017). In Vitro Cytotoxic And Antioxidant Activities Of Phenolic Components Of Algerian Achillea Odorata Leaves., 10(3), 403-409.

Brasil, ., Mapa, M., Instrução, D. A. P. E. A., \& Normativa. (2008). Regulamento Técnico Da Amêndoa De Cacau. Diário Oficial [Da] República Federativa Do Brasil., 119(1), 14.

Caporaso, N. E., \& Al. (2018). Index, Polyphenol Content And Antioxidant Activity In Single Cocoa Beans. Food Chemistry, V.Index, Polyphenol Content And Antioxidant Activity In Single Cocoa Beans. Food Chemistry. Hyperspectral Imaging For Non-Destructive Prediction Of Fermentation, 258(November), 343-351.

Caprioli, G. E., Al, \& International Journal Of Food Sciences And Nutrition. (2016). Nutritional Composition, Bioactive Compounds And Volatile Profile Of Cocoa Beans From Different Regions Of Cameroon. Nutritional Composition, Bioactive Compounds And Volatile Profile Of Cocoa, 67(4), 422-430.

Delgado-Ospina, J. E., \& Al. (2020). Effect Of Fermentation, Drying And Roasting On Biogenic Amines And Other Biocompounds In Colombian Criollo Cocoa Beans And Shells. Foods., $9(4), 1-20$.

Franco, B. D. G., De, M., Landgraf, M., \& Alimentos, M. D. (1996). São Paulo: Atheneu.

Gao, X. E., \& Al. (2000). Changes In Antioxidant Effects And Their Relationship To Phytonutrients In Fruits Of Sea Buckthorn (Hippophae Rhamnoides L.) During Maturation. Journal Of Agricultural And Food Chemistry., 48(5), 1485-1490.

Godočiková, L. E., Al, \& Journal Of Food And Nutrition Research. (2019). Biological Activity, Antioxidant Capacity And Volatile Profile Of Enriched Slovak Chocolates., 58(3), 283293.

Gu, F. E., Al, \& Foods. (2013). Comparison Of Cocoa Beans From China., 2(2), 183-197.

Jia, C. H., Shin, J. A., \& Lee, K. T. (2019). Evaluation Model For Cocoa Butter Equivalents Based On Fatty Acid Compositions And Triacylglycerol Patterns. Food Science And Biotechnology, 28(6), 1649-1658. 
Lima, L. J. R., Al, \& Applied And Environmental Microbiology. (2012). Microbiota Dynamics And Diversity At Different Stages Of Industrial Processing Of Cocoa Beans Into Cocoa Powder., 78(8), 2904-2913.

Marseglia, A. E., Al, \& Cacao L.) From Different Geographical Origins. Food Research International. (2020). Volatile Fingerprint Of Unroasted And Roasted Cocoa Beans. (Vol. 132, p. 109101). Theobroma.

Mustiga, G. M., \& Al. (2019). Identification Of Climate And Genetic Factors That Control Fat Content And Fatty Acid Composition Of Theobroma Cacao L. Beans. Frontiers In Plant Science., 10(October), 1-20.

Naik, B., Kumar, V., \& Engineering And Technology. (2014). Cocoa Butter And Its Alternatives: A Reveiw. Journal of Bioresource, 1, 7-17.

Nurhayati, N., \& Apriyanto, M. (2021). Sensory Evaluation Of Chocolate Bar Production Materials Of Dry Cocoa Seeds In Various Fermentation Treatments. Czech Journal of Food Sciences, 39(1), 58-62.

Oracz, J., \& Nebesny, E. (2019). Effect Of Roasting Parameters On The Physicochemical Characteristics Of High-Molecular-Weight Maillard Reaction Products Isolated From Cocoa Beans Of Different Theobroma Cacao L. Groups. European Food Research And Technology., 245(1), 111-128.

Oyazu, M., \& Journal Of Nutrition. (1986). M. Studies On Product Of Browning Reaction Prepared From Glucose Amine. Japan ., 44, 307-315.

Peláez, P. P., Guerra, S., \& Contreras, D. (2016). Changes In Physical And Chemical Characteristics Of Fermented Cocoa (Theobroma Cacao) Beans With Manual And Semi- Mechanized Transfer, Between Fermentation Boxes. Scientia Agropecuaria., 07(02), 111119.

Resolução RDC No 12, De 02 De Janeiro De . (2001). Aprova O Regulamento Técnico Sobre Padrões Microbiológicos Para Alimentos. Diário Oficial [Da] República Federativa Do Brasil, 139(7).

Rezende, F. E., Al, \& Anti-Alzheimer, Antimicrobial, And Antioxidant Potential. Chemical Engineering Transactions. (june. 2019). Edible Flowers As Innovative Ingredients For Future Food Development., 75, 337-342.

Sande, D. E., Al, \& Contend And Nutraceutical Potential As Antioxidant. Journal Of Applied Pharmaceutical Science. (2016). Roots From Mulberries (Morus Alba) Natural And Hybrids Varieties: Phenolic ., 6(11), 063-069.

Silva, D., \& Al, N. E. (2018). Microbiological Examination Methods Of Food And Water: A Laboratory . Manual. Second Edi Ed. Boca Raton: CRC Press.

Takahashi, J. A., Al, \& Food Research International. (2020). Edible Flowers: Bioactive Profile And Its Potential To Be Used In Food Development., 129, 108868.

Torres-Moreno, M., \& Tarrega, A. (2021). Blanch, C. Effect Of Cocoa Roasting Time On Volatile Composition Of Dark Chocolates From Different Origins Determined By HS-SPME/GCMS. CYTA - Journal Of Food., 19(1), 81-95.

Urbańska, B., \& Kowalska, J. (2019). Comparison Of The Total Polyphenol Content And Antioxidant Activity Of Chocolate Obtained From Roasted And Unroasted Cocoa Beans From Different Regions Of The World. Antioxidants., 8(8).

Valiente, C. E., \& Al. (1994). Roasting Effects On Dietary Fiber Composition Of Cocoa Beans. Journal Of Food Science. Journal, 59(1), 123-124.

Zzaman, W., Yang, T. A., \& Moisture. (2014). Moisture, Color And Texture Changes In Cocoa Beans During Superheated Steam Roasting. Journal of Food Processing And Preservation, 38(3), 1364-1370. 